\title{
Environmental Factors Associated with Nitrate Poisoning in Livestock in Botswana
}

\section{Binta $\mathrm{MG}^{1 *}$ and Mushi EZ ${ }^{2}$}

${ }^{1}$ National Veterinary Laboratory, Botswana

${ }^{2}$ Botswana College of Agriculture, Botswana

\begin{abstract}
Some cases of sudden deaths in cattle, sheep and goats reported to the National Veterinary Laboratory, Gaborone were investigated. The clinical signs included: stupor, weakness, staggering, trembling, dyspnoea (difficulty in breathing), salivation, diarrhoea, and convulsions for those in extremis. The most consistent sign was the muddy coloured mucous membranes. Necropsy findings included: marked gastroenteritis and generalized congestion and petichiation in all internal body organs and chocolate brown coloured blood that clotted poorly. The presence of nitrate/nitrite in the blood of live animals, amniotic fluid, urine, ocular fluid, urine, drinking water and consumed forage were demonstrated by the diphenylamine test and subsequently confirmed by Gries test. Further confirmation of nitrate/ nitrite poisoning was by response to therapeutic intervention with methylene blue using the intravenous route of inoculation.
\end{abstract}

Environmental factors that may have contributed to the poisoning episodes included, drought, high ambient temperatures, low cloud cover, soil leaching after flooding, soil moisture content and forage nitrogen content and natural geoformations associated with high nitrate content in the water.

This is the first account of confirmed cases of nitrate/ nitrite poisoning in livestock in Botswana.

Keywords: Nitrate; Livestock; Poisoning; Drought; Forage; Ground water

\section{Introduction}

Botswana which enjoys a predominantly subtropical climate lies between latitude $18 \mathrm{~S}$ and $27 \mathrm{~S}$ and longitude $20 \mathrm{E}$ and 29E. As a result, the country is largely arid to semi-arid with a preponderance of leguminous Acacia species of trees on the veldt.

Rainfall in Botswana averaging $500 \mathrm{~mm}$ per annum is generally low, erratic and unreliable. Cyclic periods of severe droughts followed by devastating floods have been recorded and evaluated using the Hashimoto criteria $[1,2]$.

The authors have also alluded to the extremes of temperatures in summer and winter with morning frosts characterizing the latter particularly in the Kalahari desert districts of Tsabong, Hukuntsi and Ghanzi.

Nitrogen is one of the main biogeochemical elements whose cycle constitutes one of the life lines of planet Earth. Whereas nitrogen compounds in most environments play a beneficial role, the presence of such compounds in water and plants is generally detrimental.

Under normal conditions, nitrate ingested by ruminant livestock, such as cattle, sheep and goats, is converted to ammonia and then bacterial protein in rumen by bacteria. The steps in the process involve reduction of nitrate to nitrite which is further broken into ammonia used to synthesize amino acids. The latter being building blocks for protein synthesis. When livestock consume excess nitrogen either through water or feed, it is termed nitrate poisoning [3].

In Botswana, there have been reports of sudden deaths among domestic ruminants, particularly during extremes of heat, cold and after heavy rainfall attributed to possible nitrate/nitrite poisoning.

The aim of the present study was to investigate reported cases of suspect nitrate/nitrate poisoning in order to establish the cause and the instigating factors with a view to formulating preventive measures to curb stock losses.

\section{Materials and Methods}

In the period 2000 to 2005 a follow up of all cases of unexplained sudden deaths among cattle, sheep and goats on farms in Botswana, reported to the National Veterinary Laboratory, Gaborone was conducted.

The follow up protocol involved obtaining concise information from the attending field Veterinarian data on mortality and morbidity rates, presenting clinical signs, findings at necropsy and response to therapy.

The two key steps to get accurate diagnosis were to ensure that the samples were representative and loss of nitrate was minimized between sampling and laboratory diagnosis.

The samples that were collected and analysed were water, feeds and body fluids.

\section{Water}

Water implicated in poisoning of livestock was collected from boreholes, wells, drinking troughs, in special sterile 1 litre plastic bottles

*Corresponding author: Binta MG, 1National Veterinary Laboratory, Private Bag 0035, Gaborone, Botswana, E-mail: mary@naftec.org

Received October 10, 2012; Accepted November 09, 2012; Published November 14,2012

Citation: Binta MG, Mushi EZ (2012) Environmental Factors Associated with Nitrate Poisoning in Livestock in Botswana. J Pet Environ Biotechnol 3:131. doi:10.4172/2157-7463.1000131

Copyright: $\odot 2012$ Binta MG, et al. This is an open-access article distributed unde the terms of the Creative Commons Attribution License, which permits unrestricted use, distribution, and reproduction in any medium, provided the original author and source are credited. 
provided by the analyzing laboratory. To obtain a good sample from a well, the water was allowed to run until water in pipes and pressure was discharged.

\section{Silage}

Samples were taken during the unloading process. At least 5 separate samples were taken while unloading. These were well mixed and $1 \mathrm{~kg}$ of silage was taken for testing. Silage samples were frozen because it is difficult to dry without losing volatile materials.

\section{Green chopped forage}

The part of the plant sampled was dependent on the grazing system. For limit grazing, maize (Zea mays), sorghum (Sorghum vulgare), sorghum-sudan grass only leaves were sampled. Several handfuls from different loads or different parts of the load were collected. These were mixed thoroughly and $1 \mathrm{~kg}$ removed for testing.

\section{Standing corn or sorghum}

For rotational grazing or single-field grazing system, both leaves and stems were sampled. Samples were taken from the lower one third of maize, grain, sorghum (Sorghum vulgare) and sorghum sudan stalks.

At least 15 randomly picked whole plants were selected. They were cut at the same height as the field chopper. Then, they were chopped into one -half inch lengths and mixed well to make a composite sample. $1 \mathrm{~kg}$ was then removed for testing.

Care was taken not to mix samples from different areas. Different composite samples were created for different areas of collection.

\section{Sampling bales}

To sample bales, the bale was split open and the lower stems of individual plants collected. A bale probe was used to collect representative core samples in cases where the bale was ground as stover before being fed.

All the forage samples were submitted to the laboratory in clean paper bags and not plastic ones because the high moisture content would cause the samples to mold which might have interfered with the nitrate analysis.

\section{Tissues collected at necropsy}

Necropsy was conducted on carcases of nitrate poisoning suspect animals within 6 hours after death. Various tissues namely musculature, gastrointestinal tract, myocardium, liver, kidney, lungs, abomasum and brain were collected in $10 \%(\mathrm{v} / \mathrm{v})$ formol saline for routine histopathology using Haematoxylin and Eosin stain.

\section{Body fluids}

Ocular: Ocular (aqueous humour) fluid of the eyeball collected from dead animals was placed into a $10 \mathrm{ml}$ plastic bottle of capacity 10 $\mathrm{ml}$, using a syringe. The bottle was tightly sealed with a screw cap and was transported to the laboratory on ice maintaining a low temperature of about $4^{\circ} \mathrm{C}$ during transportation.

Serum: Whole blood was collected from jugular vein of animals showing signs suggestive of nitrate poisoning. The blood without anticoagulant was allowed to clot at room temperature and serum was decanted off after retraction of the blood clot.

Nitrate in serum is stable for one week of refrigeration.

Heparinised blood: Whole blood collected from live morbid animals, into vacutainer tubes containing heparin as anticoagulant was used in testing for nitrate. The colour of the heparinised blood was used as a diagnostic indicator of nitrate poisoning in ruminants.

Heparinized blood was collected within two hours of death and in order for this test to be valid; otherwise, blood must be rapidly frozen minimize spontaneous reduction of methemoglobin back to haemoglobin

Blood clots collected from the heart at necropsy were also used in the test in cases where there were no live sick animals.

Amniotic fluid: Amniotic fluid was collected aseptically by centesis from en utero foetuses at maternal necropsy.

\section{Urine samples}

This was collected aseptically from the urinary bladder of animals within 1 hour of death, using a $20 \mathrm{ml}$ sterile syringe fitted with an $18 \mathrm{G}$ needle. Urine samples were collected from live moribund animals using a sterile urinary catheter.

\section{Whole plants for identification}

Plants suspected to have caused nitrate poisoning were collected from around the farm. They were placed between two cardboards and compressed to preserve the botanical characteristics of the plant. These were sent to the National Museum in Gaborone for identification.

\section{Laboratory Testing of Samples}

\section{Diphenylamine test}

A preliminary field test using $1 \%(\mathrm{w} / \mathrm{v})$ diphenylamine blue in concentrated sulphuric acid was used to qualitatively screen forages for potential harm [4]. Briefly, $0.5 \mathrm{~g}$ of diphenylamine was placed in a glass flask containing $20+0.1 \mathrm{ml}$ of sterile distilled water. While stirring slowly, $88 \mathrm{ml}$ of concentrated sulphuric acid was added to dissolve the diphenylamine and this generated heat. The reagent was allowed to cool before being placed in dropper bottles.

Diphenylamine $(1 \% \mathrm{w} / \mathrm{v})$ was dissolved in concentrated sulphuric acid was added to the same amount of the sample to be tested. Potassium nitrate $(1 \% \mathrm{w} / \mathrm{v})$ was used as a positive control. However, since the same reaction can be obtained with other oxidants further testing using Gries test was conducted on the suspected material.

\section{Gries test for nitrites}

The test was conducted as previously described [5]. Briefly, reagent 1 was prepared by dissolving $1 \pm 0.1 \mathrm{~g}$ of sulphanilic acid in 75 $\mathrm{ml}$ distilled water and $25 \pm 0.1 \mathrm{ml}$ of glacial acetic acid. Reagent II is prepared by boiling $3 \pm 0.1 \mathrm{~g}$ of $\alpha$-napthylamine in $70 \mathrm{ml}$ water. This was filtered, and then $30 \mathrm{ml}$ of glacial acetic acid was added. After some time, the acetic acid decomposes and turns pink. The two reagents are mixed in a 1:1 ratio before use. Add the solution to be tested drop by drop to $2 \mathrm{ml}$ of reagent. If nitrites are present, the sample turns red. The test is sensitive because the reaction is specific. Further testing was done using the indole test whereby a drop of the sample is treated with 10 drops of a $0.015 \%(\mathrm{w} / \mathrm{v})$ solution of indole in ethanol and 5 drops of concentrated sulphuric acid.

\section{Therapeutic intervention}

Treatment of cattle as described by some authors [6] involves administration of $8.8 \mathrm{mg} / \mathrm{kg}$ dose of a $1 \%$ isotonic methylene blue, using the intravenous route of inoculation is effective if administered 


\begin{tabular}{|l|l|l|l|l|}
\hline Disrict & Cases & Mortality & $\begin{array}{l}\text { Forage } \\
\text { (Cases) }\end{array}$ & $\begin{array}{l}\text { Water } \\
\text { (Cases) }\end{array}$ \\
\hline Francis Town & 2 & 2 & 0 & 2 \\
\hline Ghantsi & 6 & 413 & 1 & 5 \\
\hline Jwaneng & 3 & 36 & 2 & 1 \\
\hline Kanye & 2 & 4 & 2 & 0 \\
\hline Lobatse & 2 & 13 & 0 & 2 \\
\hline Maun & 2 & 13 & 2 & 0 \\
\hline Mahalapye & 1 & 1 & 1 & 0 \\
\hline Molepolole & 2 & 16 & 0 & 2 \\
\hline Tsabong & 2 & 11 & 0 & 2 \\
\hline Total & $\mathbf{2 2}$ & $\mathbf{5 0 5}$ & $\mathbf{8}$ & $\mathbf{1 4}$ \\
\hline
\end{tabular}

Table 1: Reported Cases of Nitrate Poisoning In Livestock in Botswana 2000-2005.

soon after symptoms appear. Sheep may need $20 \mathrm{mg} / \mathrm{kg}$. Repetition of this regimen may be done after an interval of 6 to 8 hours. Methylene blue is not licensed for use in food animals in Botswana.

\section{Results}

In the period 2000 to 2005 , twenty two cases of suspected nitrate poisoning involving about 505 head livestock comprising beef cattle, sheep and goats were reported to the National Veterinary Laboratory, Gaborone, Botswana, either by field veterinarians or the farmers themselves (Table 1). Young calves and pregnant cows were apparently more susceptible than adult non-pregnant cows and sheep. Donkeys on the affected farms did not show any signs of sickness.

\section{Clinical signs}

The attending field veterinarians reported that affected animals were showing the following signs: standing alone in a stupor, weakness, staggering, trembling, dyspnoea (difficulty in breathing), salivation, diarrhoea, abdominal guarding and bloat in a few cases. Clinical examination revealed that all the visible mucous membranes of sick animals were a muddy colour with some degree of cyanosis, a rapid pulse and those in extremis were either convulsing or comatose before death intervened. Clinical signs were accentuated by exercise.

Some farmers in Ghanzi district reported sporadic abortions among adult pregnant animals (cows and goats) that survived the acute phase of the disease, two weeks after ingestion of nitrate. Unthriftiness, reduced milk production and heat intolerance were also reported among livestock suffering from chronic nitrate intoxication.

\section{Post-mortem findings}

At post- mortem, there was severe reddening and stripping of the rumen, abomasums and intestinal linings. Dark chocolate brown blood that clotted poorly was seen in the mesenteric cavity. Petechiae (pinpoint) haemorrhages in internal organs, gastroenteritis and accumulation abomasal congestion were pronounced. There was severe reddening and stripping of the stomach and intestinal linings. There were blanched areas on the epicardial surfaces. Pleural surfaces of animals that succumbed were a crimson red colour. Venous blood drawn from the jugular vein was also brownish and did not clot easily.

\section{Laboratory findings}

In the diphenylamine and Gries field tests for forage, water, ocular and amniotic fluid samples a deep blue and pink colour were observed in the respective tests in all the samples tested, which was suggestive of the presence of nitrite.

\section{Plant identification}

Various plant species namely, young sorghum (Sorghum vulgare) plants, Amaranthus retroflexus, young wilted maize (Zea mays) plants, Ondentia species. Other grasses collected and identified in this study included star grass (Cynodon nlemfuensis Vanderyst).

\section{Diagnosis by response to therapy}

Response of affected cattle, sheep and goats to methylene blue at a dosage rate of $15 \mathrm{mg} / \mathrm{kgb} . \mathrm{w}$ using the intravenous route of administration was used as a diagnostic tool for nitrate -nitrite poisoning in affected animals.

It was reported that when animals were immediately removed from suspect water or herbage and given alternative sources of water, hay or herbage no new cases were reported on affected farms. Animals were handled quietly to avoid excessive stimulation.

Symptomatic treatment involving cardiac stimulants, gastric antacids, and oral antibiotics to reduce nitrate production was instituted.

\section{Discussion}

The diagnosis of nitrate poisoning in 22 cases involving cattle, sheep and goats was made based on the positive results of the diphenylamine and Gries tests on body fluids collected at post-mortem, implicated water and forage, characteristic lesions at necropsy and suggestive clinical signs. These findings were previously corroborated by various authors [7]. Furthermore, the chocolate brown - coloured blood collected upon venipuncture in live moribund animals was pathognomonic of nitrate poisoning $[3,8]$. The latter eliminated the possibility of cyanide poisoning, the most plausible differential diagnosis.

In the present study, cases of abortion reported among the survivors could have been attributed to transplacental diffusion of nitrate into the foetus resulting in methaemoglobinaemia. These field observations have been documented by several authors $[6,9]$. Corollary to this were reports in this study of neonatal and perinatal calf mortalities as well as low birth weights, reproductive failures, reduced lactation and hypothyroidism due to maternal chronic nitrate poisoning.

In this investigation, observed species predisposition pertaining to nitrate/nitrite poisoning previously documented [8], could have been attributed to reduced conversion of haemoglobin, the oxygen carrying moiety in the blood to methaemoglobin by sheep. In cattle, when the rate of reduction of nitrate to nitrite is faster than conversion of nitrite to ammonia, accumulation of nitrite occurs. Subsequently, nitrite is absorbed into circulation. Nitrite combines with haemoglobin, to form methaemoglobin responsible for the chocolate - brown colour of blood and visible mucous membranes in affected animals. Since the latter has little oxygen carrying capacity this could explain occurrence of fatal respiratory embarrassment observed by the farmers and field veterinarians in animals in extremis.

Sheep did not succumb to the poisoning as much as cattle in the present study, and also donkeys and horses were consistently spared.

It is speculated that the previously established protective effect of high energy rations such as corn against nitrate/nitrite poisoning [8] probably accounted for absence of cases in dairy cows.

The possible sources, effects, instigating and exacerbating factors of nitrate poisoning in ruminants have been extensively documented by several authors $[7,8,10,11]$. 
Interrelated environmental factors that may have contributed to the poisoning episodes included, anthropogenic activities, drought, high ambient temperatures, low cloud cover, soil leaching after flooding, soil moisture content and forage nitrogen content, and natural geoformations associated with high nitrate content in the water.

Anthropogenic activities comprising feedlots, kraals, heavy fertilizer and herbicide application to plants, inappropriate on- site sanitation and landfills have been known to increase the nitrate content of soil thus polluting underground water systems in towns and villages by leaching and percolation $[12,13]$. Documentary evidence to this effect in Botswana has been provided by these authors.

Ground water is usually the cheapest and most sustainable source of clean water for rural areas in Southern Africa including Botswana [14] . However in Southern Africa including Botswana, natural hot spots of high nitrate levels in the Limpopo River Basin have been identified even where there is no extensive anthropogenic activity $[15,16]$.

The natural occurrence of nitrate in ground water is a worldwide phenomenon and a significant increase has been noted globally in Southern Africa including Botswana, with geoformations harboring nitrate rich water [17]. Such geological formations can only serve as a primary source of nitrogen in exceptional cases where ammonium ions are incorporated in rock minerals to be released by weathering and oxidized to nitrate.

The apparent correlation between occurrence of high nitrate levels in certain geological formations such as the Ghanzi group in Botswana and its equivalent (eg the Nossib group in Namibia, Springbok Flats in South Africa) is due to secondary characteristics of the geological formations and associated factors allowing enrichment with nitrate derived from other sources such as anthropogenic activity.

In our study, some water samples particularly implicated in nitrate poisoning was collected from boreholes and wells in these areas mostly from Ghanzi district. This could in part have contributed to the livestock mortalities.

Common causes of high nitrate levels in water include shallow wells contaminated with surface water, water containing animal wastes, feedlots, septic tank disposal fields, surface run off from heavy rains after fertilization with ammonium nitrate. As mentioned, these are as a result of anthropogenic activity. Consequently, excess nitrates are also more likely to be found in ground water under low areas and waterways. Water samples from shallow, dug, bored and drilled wells are more frequently found to have excess nitrate level than deeper wells. However, in Ghanzi district some boreholes are as deep as $200 \mathrm{~m}$ and these have been associated with sporadic nitrate poisoning in cattle.

In the current investigation, yet another possible source of nitrate poisoning was forage both fodder and poisonous weeds used or encountered on farms or grazing areas. Young sorghum plants, grass and Amaranthus retroflexus were identified and tested positive for nitrate/nitrite in both the diphenylamine and Gries tests. Some plants such as Sorghum cultivars, a weed Red-root pigweed (Amaranthus retroflexus) known to accumulate high levels of nitrate in the stems especially if growing on soil rich in nitrogen $[6,18,19]$ and during drought [20] were implicated in the present study. Some of the cases reported in this investigation involved feeding either frost damaged or wilted young sorghum plants. It was speculated that Amaranthus retroflexus weed may have been inadvertently incorporated into bales of hay at the time of cutting $[19,21]$.

The leaves and flowers of another plant Ondetia linearis related to
Geigeria species (Vermeerbos) known to contain high levels of nitrate [22] was identified on one of the affected farms, located in Ghanzi district very close to the Botswana Namibia border where the plant is endemic.

Cyclic drought is one of the major environmental factors which probably contributed most to the cases of nitrate poisoning recorded particularly in Ghazi district located in the Kalahari desert. The resulting high ambient day time temperature and low cloud cover in daytime predisposes to increased damage of the natural habitat thus removing vegetation cover. Vegetation in the Kalahari desert is scrub comprising mainly Acacia species of trees. Which are leguminous. The exposed ground is vulnerable to diurnal temperatures in the Kalahari desert thus accelerating top soil degradation to sand. Sandy soils are prone to leaching particularly, where there has been accumulation of cow manure in the feedlots.

Most of the cases of poisoning in Ghanzi were recorded in summer under drought conditions with reduced cloud cover and high rate of evaporation. This reduces surface water which usually charges boreholes. It was speculated that perhaps, reduced levels of water in the deep boreholes in Ghanzi district resulted in the concentration of nitrate borehole.

The impact of droughts in Southern Africa has been studied [23]. The cyclic droughts in southern Africa including Botswana have predisposed the region to not only unreliable rainfall, arid environment but also catastrophic flood following drought leaches nitrates into surface run off which percolates into ground water $[2,24,25]$. Percolation of nitrogen rich water into the underground system could in part have contributed to cases of nitrate poisoning in livestock drinking water from boreholes in Ghanzi district.

Drought and winter stress, deficiencies of essential nutrients like phosphorus, sulphur and molybdenum low soil moisture, application of herbicide and fertilizers as well as excessive soil nitrogen aggravate nitrate accumulation in various plants due to reduced nitrate utilization. Pastures in Botswana particularly in Ghanzi district particularly around feedlots are treated with fertilizer due to loss in productivity sequel to droughts and inclement weather conditions characteristic of this area. Wilted, growth retarded and undernourished plants are known to accumulate potentially toxic levels of nitrate in their stems.

The first rains after a protracted dry spell, enhances sudden rapid growth of plants resulting in rapid absorption of nitrates. Whereas photosynthesis converts nitrates into products the plant can use, slowed photosynthesis due to overcast conditions with prevailing warm soil temperatures results in continued uptake of nitrates from the soil but reduced breakdown of nitrates. Short rains after veldt fires common in Botswana also induce rapid growth of grasses particularly nitrate accumulators. Consequently, accumulation of potentially toxic levels of nitrate in the leaves and shoots occurs.

Rare accidental poisoning due to leaching of inadvertently abandoned nitrate explosives into surface water pools used to water animals accounted for one case of poisoning where anthropogenic activity was not reported in this investigation.

It has been reliably established that good management practices on the farm, frequent monitoring of water and forage for nitrate levels, prevention of pollution of underground water reserves through proper sanitation, avoiding over grazing, use of true sorghum hybrids cultivars and test forage frequently for toxic levels of nitrate.

Gradual introduction of hungry stock into a young sorghum field 
Citation: Binta MG, Mushi EZ (2012) Environmental Factors Associated with Nitrate Poisoning in Livestock in Botswana. J Pet Environ Biotechnol 3:131. doi:10.4172/2157-7463.1000131

particularly when moisture stressed is advocated. Avoidance of access to risky forage prevents accidental poisoning by nitrate accumulating forage.

Since synergy between water nitrate levels and marginally high forage nitrate predisposes livestock to poisoning, water should not contain high nitrate levels. Green chop that has heated after cutting should not be fed to livestock. Never feed moldy hay and plenty of roughage should be given to stock before grazing sorghum. Monitoring of animals for signs of poisoning should be done for as long as two days after release into a sorghum field. It has been established that fermentation during ensiling reduces accumulation of nitrates. The stover cutter raised 6 inches above the ground prevents incorporation of lower stems with the highest accumulation of nitrates.

Therapeutic intervention by administration of methylene blue to animals showing signs of poisoning using the intravenous route of inoculation reduce mortality for the dye converts the methaemoglobin back to oxygen-carrying haemoglobin [6].

It should however be noted that assessment of the extent of nitrate poisoning in livestock countrywide would warrant a separate study as many cases may go unreported.

\section{Acknowledgements}

This paper was published with the permission of the Director of Veterinary Services, Botswana.

\section{References}

1. Central Statistics Office (CSO) (2000) Botswana environmental statistics Department of Printing and Publishing services, Gaborone, Botswana.

2. Tsheko R (2003) Rainfall reliability, drought and flood vulnerability in Botswana Water SA 29: 389-392.

3. Sidhu PK, Bedi GK, Meenakshi, Mahajan V, Sharma S, et al. (2011) Evaluation of factors contributing to excessive accumulation in fodder crops leading to illhealth in Dairy animals. Toxicol int 18: 22-26.

4. Kahn CM (2005) The Merck Veterinary Manual. $9^{\text {th }}$ edition, New Jersey: Toxicology: Nitrate and nitrite poisoning 2423-2426.

5. Bartik M, Piskac A (1981) Veterinary Toxicology: In Developments in Anima and Veterinary Sciences: Elsevier Scientific Publishing Company, Amsterdam.

6. Radostits OM, Gay CC, Blood DC, Hinchcliff KW (2000) Veterinary Medicine 9th Edition, London, W.B Saunders Co. 1636-1639.

7. Stanton TL, Whitter J (2006) Nitrate poisoning : No1.610 Colorado state University : University Cooperative Extension.

8. Robson S (2007) Nitrate and nitrite poisoning in livestock. Prime fact 415 Department of Primary Industries, New South Wales.
9. Laven RA, Biggadike HJ, Allison RD (2002) The effect of pasture nitrate concentration and concentration intake after turnout on embryo growth and viability in the lactating dairy cow. Rep Domest Anim 37: 111-115.

10. Scott DF, Le Maitre DC (1998) Review of information on interactions between vegetation and groundwater. 25: 137-152.

11. Villar D, Schwartz KJ, Carson TL, Kinker JA, Barker J (2003) Acute poisoning of cattle by fertilizer-contaminated water .Vet Human Toxicol 45: 88-90.

12. Lagerstedt $E$, Jacks $G$, Sefe $F(1994)$ Nitrate in ground water and $N$ circulation in Eastern Botswana. Environmental Geology 23: 60-64.

13. Hattingh J, Classen M (2008) Securing water Quality for Life. International Journal of water Resources Development 24: 401-415

14. Holtzhausen L (2005) When Water Turns Deadly: Investigating Nitrate in SA Groundwater. Accessed on September 292012.

15. Vogel HK, Mokokwane K, Setioboko T (2004) Nitrate hotspots and salinity levels in groundwater in the Central District of Botswana. Environmental Geology Division, BGR and the Department of Geological Survey.

16. Tredoux G, Talma AS (2006) Nitrate pollution of ground water in Southern Africa In: Xu , Y and Usher B (eds) Ground water pollution in Africa, Taylor and Francis / Baikema, Leiden. The Netherlands 10: 415-416.

17. Tredoux G, Engelbrecht JFP, Israel S (2009) NITRATE IN GROUNDWATER: Why is it a hazard and how to control it? Report to the Water Research Commission by CSIR, Natural Resources and Environment, Stellenbosch, WRC report No.TT410/09.

18. Asiani MR, Vojadani M (2007) Nitrate intoxication due to ingestion of pigweed red root (Amaranthus retroflexus) in cattle. Iranian J Vet Res University of Shiraz 8: 317-318.

19. Last RD, Hill JH, Theron G (2007) An outbreak of perirenal oedema syndrome in cattle associated with consumption of pigweed (Amaranthus hybridus L). J S African Vet Assoc 78: 171-174

20. Pickrell JA, Oehme FW, Hickman SR (1991) Drought increases forage nitrate and cyanide. Vet Hum Toxicol 33: 247-251.

21. Haliburton JC (1999) Nitrate poisoning associated with consumption of forages or hay In" Howard I ( Edit) : Current Veterinary Therapy, Food Animal Practice ( $4^{\text {th }}$ Edition) Philadelphia, Saunders 278-279.

22. Craven P, Klassen E (1998) Ondentia, the problematic cousin of "vermeerbos" In: Spotlight on Agriculture, No: 9, Ministry of Agriculture, Water and Rura Development, Directorate of Agricultural Research and Training, Namibia

23. Vogel C, Laing M, Monnik K (1999) Impacts of drought in South Africa 1980 1994 In: Hazards and disasters: a series of definitive major works.

24. Beekman HE, Saayaman L, Hughes SP (2009) Vulnerability of water resources to Environmental change in Southern Africa. United Nations Environmental program (UNEP), Nairobi, Kenya

25. Food and agricultural Organisation of the United nations ( FAO) (2004) Drough impact mitigation and prevention in the Limpopo River Basin. A situational analysis. Rome, Italy. 